\title{
ISOLAMENTO SONORO AÉREO DE PARTIÇÕES VERTICAIS DE UM APARTAMENTO EM MACEIÓ-AL-BRASIL
}

\section{AIRBORNE SOUND INSULATION OF VERTICAL PARTTTONS OFANAPARTMENT INMACEIÓ-AL-BRAZIL}

\author{
Rafaella Cristina Teixeira Penedo 1 \\ Universidade Federal de Alagoas, Faculdade de Arquitetura e Urbanismo, Maceió, AL, Brasil, rafapenedo@yahoo.com.br \\ Maria Lúcia Gondim da Rosa Oiticica ${ }^{2}$ \\ Universidade Federal de Alagoas, Faculdade de Arquitetura e Urbanismo, Maceió, AL, Brasil, mloiticica@hotmail.com
}

\section{Resumo}

A arquitetura brasileira tem apresentado constantes mudanças nas técnicas e nos materiais de construção com reflexos na qualidade das construções. No caso do isolamento sonoro de habitações, o resultado, em geral, tem sido negativo. Com o advento da norma de desempenho de edificações habitacionais, a NBR 15575, publicada no ano de 2013 pela Associação Brasileira de Normas Técnicas - ABNT e que estabelece os requisitos mínimos para os diversos elementos de construção em favor do desempenho dos edifícios, as empresas de construção civil terão que adequar a nova construção aos limites e aos requisitos estabelecidos pela norma. O objetivo geral deste trabalho é avaliar, por meio de medições de campo, o nível de isolamento sonoro (ruído aéreo) de duas partições verticais da sala de estar de um apartamento em Maceió-AL-Brasil através de dois parâmetros estabelecidos na NBR 15575: a Diferença Padronizada de Nível Ponderada (D'n'ww) e a Diferença Padronizada de Nível Ponderada a $2 \mathrm{~m}$ de distância da fachada (D'2m,nT,w). Verificou-se que os níveis de isolamento sonoro aéreo encontrados são inferiores aos recomendados pela norma, demonstrando a insuficiência, do ponto de vista acústico, dos materiais utilizados na composição das paredes. É clara a necessidade, não apenas, de avaliar e monitorar o desempenho acústico, mas também de maior preocupação com estratégias de projeto e de intervenções construtivas que proporcionem aos usuários condições adequadas de conforto e de privacidade.

Palavras-chave: Isolamento sonoro. Avaliação de desempenho. Desempenho acústico.

\begin{abstract}
Brazilian Architecture has shown constant changes in techniques and construction materials reflecting on the quality of buildings. In the case of sound insulation of dwellings, the result, in general, has been negative. With the advent of the NBR 15575, published in 2013 by the "Associação Brasileira de Normas Técnicas - ABNT", which establishes minimum requirements for the various elements of construction in favor of the performance of buildings, construction companies will have to adapt the new construction to the limits and requirements it establishes. The general objective of this work is to evaluate, through field measurements, the level of sound insulation (airborne noise) of two vertical partitions of the living room of an apartment in Maceio-AL-Brazil on two parameters established in NBR 1557: Weighted Standardised Sound Level Difference (D'nT,w) and Weighted Standardised Sound Level Difference of the façade (D'2m,nT,w). It has been found that airborne sound insulation levels are lower than those recommended by the standard, demonstrating the inadequacy, from the acoustic point of view, of the materials used in the composition of the walls. It's clear the need to assess and to monitor the acoustic performance, and also to present design strategies and constructive interventions for the comfort and privacy of users.
\end{abstract}

Keywords: Sound insulation. Performance evaluation. Acoustic performance.

How to cite this article:

PENEDO, Rafaella Cristina Teixeira ; OITICICA, Maria Lúcia G. Isolamento sonoro aéreo de partições verticais da sala de estar de um apartamento em Maceió-AL Brasil. PARC Pesquisa em Arquitetura e Construção, Campinas, v. 5, n. 2, p. 7-14, jul./dez. 2014 


\section{Introdução}

Em resposta à difusão das inovações tecnológicas, a Arquitetura brasileira tem apresentado uma série de modificações nas técnicas e nos materiais de construção com reflexos diversos na qualidade das edificações. No caso da qualidade do isolamento sonoro de habitações, esses reflexos, de modo geral, têm sido negativos.

A avaliação de desempenho, que permite analisar, de forma objetiva, se um sistema ou um processo construtivo está cumprindo a função a que se destina de forma adequada, de acordo com parâmetros préestabelecidos (ASSOCIAÇÃO BRASILEIRA DE NORMAS TÉGNICAS, 2013), é uma importante ferramenta do projetista. No Brasil entrou em vigor em 2013 a versão mais recente da NBR 15575 (ASSOCIAÇÃO BRASILEIRA DE NORMAS TÉCNICAS, 2013), que apresenta critérios para avaliações de desempenho de residências, em diversos aspectos, incluindo o conforto acústico.

Este trabalho pretende, através de medições em campo, verificar se os sistemas de vedações verticais da sala de estar do apartamento em estudo apresentam desempenho acústico em conformidade com a NBR 15575 (ASSOCIAÇÃO BRASILEIRA DE NORMAS TÉCNICAS, 2013), adotando-se como critério o nível de isolamento de duas partições a ruídos aéreos: a parede que divide as salas de estar dos apartamentos vizinhos e a da fachada. Elas estão expostas a fontes sonoras que não podem ser controladas pelo morador do apartamento: ruídos do apartamento vizinho e ruídos externos (tráfego, oriundos do uso da área de lazer, dentre outros).

\section{Considerações teóricas}

\section{Avaliações de desempenho acústico através de ensaios em campo}

A avaliação de desempenho é uma importante ferramenta de auxílio à elaboração de projetos. Ela permite analisar, de forma objetiva, se um sistema ou um processo construtivo está cumprindo a função a que se destina, de acordo com parâmetros pré-estabelecidos (ASSOCIAÇÃO BRASILEIRA DE NORMAS TÉGNICAS, 2013).

$\mathrm{O}$ avaliador deve conhecer os principais parâmetros de desempenho acústico, assim como os critérios de ruído para as edificações residenciais, estabelecidos em leis e em normas técnicas, nacionais e internacionais, que, dentre outras questões, define métodos de medição e de avaliação do isolamento acústico.
Os parâmetros acústicos são características específicas que possibilitam a análise do desempenho dos ambientes. Os que serão adotados neste estudo serão apresentados na seção "Materiais e métodos". A NBR 15575 (ASSOCIAÇÃO BRASILEIRA DE NORMAS TÉCNICAS, 2013) apresenta três métodos para avaliar o isolamento sonoro aéreo: sendo dois para ensaios em campo, os métodos de engenharia e de avaliação simplificado; e um para ensaios em laboratório, o método de precisão.

Em laboratório são feitos testes isolados em componentes, elementos e em sistemas construtivos, havendo um controle das condições ambientais, como temperatura e umidade relativa, por exemplo. Já nas medições em campo esse controle não é possível. Assim como também não existe a possibilidade de isolar, por exemplo, uma parede do piso e da laje aos quais está ligada. Por isso, nos ensaios em campo é obtido o valor do isolamento da partição entre ambientes, levando-se em consideração todo o sistema construtivo da edificação, a área da partição, área equivalente de absorção do ambiente receptor, assim como o layout deste ambiente, dentre outros fatores (FERREIRA NETO, 2009).

Com a entrada em vigor da norma brasileira de desempenho de edificações, a NBR 15575 (ASSOCIAÇÃO BRASILEIRA DE NORMAS TÉCNICAS, 2013), a procura por medições acústicas irá aumentar, principalmente pelos ensaios em campo. As construtoras precisarão avaliar suas construções mais recentes para identificar quais medidas devem ser tomadas para melhorar o desempenho acústico dos futuros lançamentos. Além disso, as edificações habitacionais projetadas e construídas após julho de 2013 também deverão ser submetidas a ensaios de campo para verificar sua conformidade aos índices de desempenho acústico estabelecidos na NBR 15575 (ASSOCIAÇÃO BRASILEIRA DE NORMAS TÉGNICAS, 2013).

Este estudo apresenta os métodos e os resultados de medições em campo realizados com fins acadêmicos, os quais podem servir como orientação para avaliações oficiais, observando sempre a adequação às normas que regulamentam esses ensaios.

\section{Materiais e métodos}

\section{Caracterização do objeto}

O edifício a ser analisado encontra-se em uma via local, com pequeno fluxo de veículos, e a cerca de $240 \mathrm{~m}$ de uma das avenidas mais movimentadas da cidade de 
Maceió-AL, a Avenida Fernandes Lima. Porém, as barreiras físicas e a direção dos ventos predominantes (contrária a dos ruídos provenientes da avenida) reduzem a intensidade dos sons que chegam ao apartamento (Figura 1).

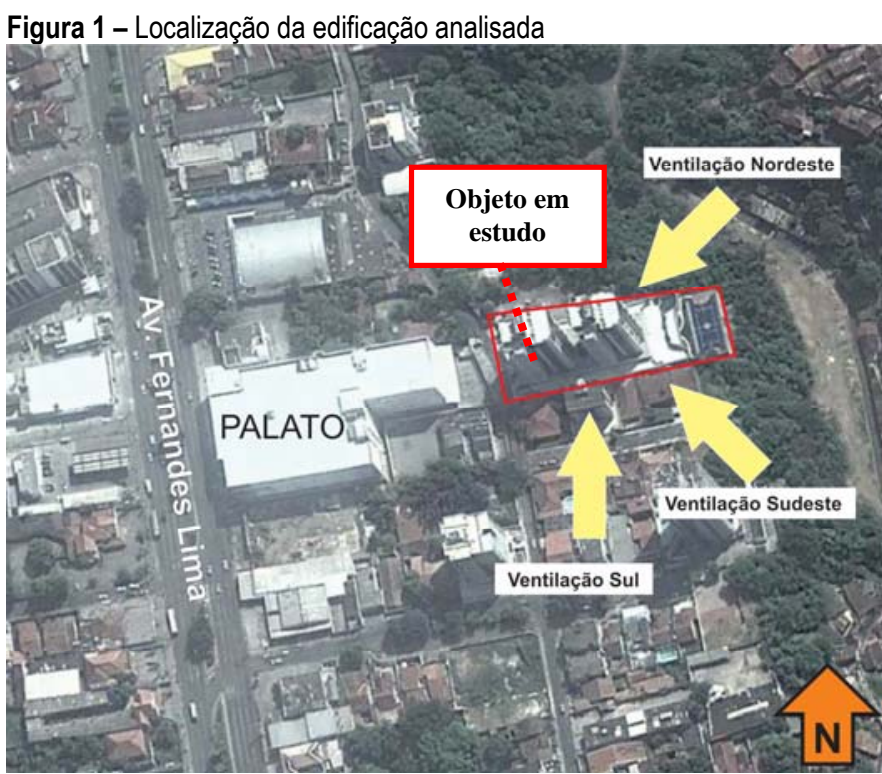

Fonte: Adaptado de Google Maps em 08 set. 2013

Avaliando a localização do objeto de estudo, o apartamento, segundo à NBR 15575 (ASSOCIAÇÃO BRASILEIRA DE NORMAS TÉGNICAS, 2013), enquadra-se na classe de ruído II, isto é: "habitação localizada em áreas sujeitas a situações de ruídos não enquadráveis nas classes I e III" (Quadro 1).

Quadro 1 -Diferença padronizada de nível ponderada da vedação externa, $D^{\prime}{ }_{2 m, n T, w}$ para ensaios de campo

\begin{tabular}{|c|c|c|c|}
\hline $\begin{array}{c}\text { Classe de } \\
\text { ruído }\end{array}$ & Elemento & $\begin{array}{c}D_{2 m, n T, w} \\
(d B)\end{array}$ & $\begin{array}{c}\text { Nível de } \\
\text { desempenho }\end{array}$ \\
\hline \multirow[b]{3}{*}{1} & \multirow{3}{*}{$\begin{array}{c}\text { Habitação } \\
\text { localizada distante } \\
\text { de fontes de ruído } \\
\text { intenso de } \\
\text { quaisquer } \\
\text { naturezas }\end{array}$} & $\geq 20$ & $M$ \\
\hline & & $\geq 25$ & 1 \\
\hline & & $\geq 30$ & $S$ \\
\hline \multirow[b]{3}{*}{ II } & \multirow{3}{*}{$\begin{array}{c}\text { Habitação } \\
\text { localizada em } \\
\text { áreas sujeitas a } \\
\text { situações de ruído } \\
\text { não enquadráveis } \\
\text { nas classes I e III }\end{array}$} & $\geq 25$ & $M$ \\
\hline & & $\geq 30$ & 1 \\
\hline & & $\geq 35$ & $S$ \\
\hline \multirow[b]{3}{*}{ III } & \multirow{3}{*}{$\begin{array}{c}\text { Habitação sujeita } \\
\text { a ruído intenso de } \\
\text { meios de } \\
\text { transporte e de } \\
\text { outras naturezas, } \\
\text { desde que esteja } \\
\text { de acordo com a } \\
\text { legislação }\end{array}$} & $\geq 30$ & $M$ \\
\hline & & $\geq 35$ & 1 \\
\hline & & $\geq 40$ & $S$ \\
\hline
\end{tabular}

Fonte: ABNT, 2013
Dentro do complexo habitacional a ser analisado, o apartamento selecionado foi o $101 \mathrm{~B}$ com $91,13 \mathrm{~m}^{2}$ de área, possuindo três quartos. Ele está situado no primeiro andar, acima do pilotis, voltado para a área de lazer (Figura 2).

O apartamento é caracterizado por paredes internas em alvenaria de blocos cerâmicos de 8 furos, com dimensões de 9x19x19 cm, emassadas com massa corrida de gesso e pintadas com pintura acrílica. A alvenaria das vedações externas é também em blocos cerâmicos de 8 furos revestidos com pastilhas cerâmicas. Já as esquadrias utilizadas são em perfil de alumínio com vidro comum $4 \mathrm{~mm}$ com apenas uma camada e com aplicação de silicone na junção entre vidro e alumínio.

Figura 2 - Localização do objeto em estudo na planta baixa do pavimento tipo do bloco $B$ do seu complexo

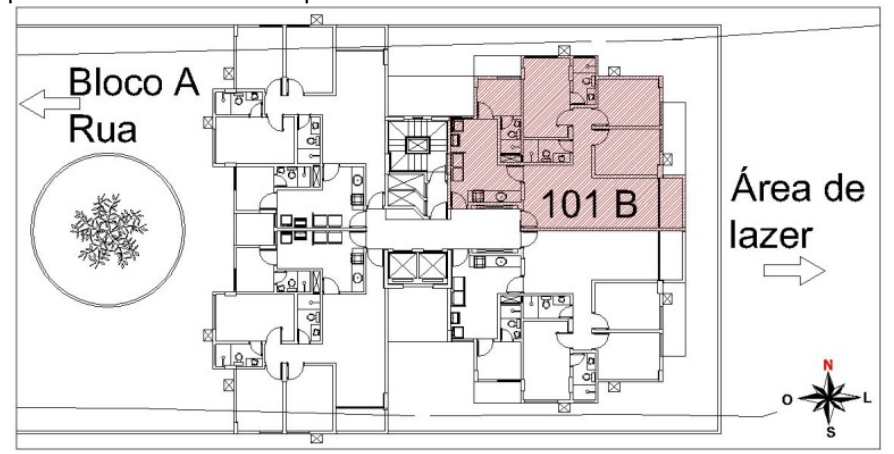

Fonte: As autoras

\section{Parâmetros para a avaliação do isolamento sonoro aéreo}

A NBR 15575 (ASSOCIAÇÃO BRASILEIRA DE NORMAS TÉGNICAS, 2013), conhecida como "Norma de Desempenho", no caso de avaliações de isolamento sonoro aéreo em medições em campo, adota os seguintes parâmetros ponderados: a Diferença Padronizada de Nível Ponderada ( $D_{\mathrm{n} T, \mathrm{w}}^{\prime}$ ) e a Diferença Padronizada de Nível Ponderada a $2 \mathrm{~m}$ de distância da fachada $\left(D^{\prime} 2 \mathrm{~m}, \mathrm{nT}, \mathrm{w}\right)$. Sendo o primeiro utilizado em avaliações de vedações verticais e horizontais internas das edificações, e o segundo para avaliações de partições de fachadas de dormitórios em edificações e de fachadas e coberturas de dormitórios em casas térreas e em sobrados. Ambos são números únicos obtidos a partir do cálculo da Diferença Padronizada de Nível ( $\mathrm{D}_{\mathrm{nT}}$ ) e da Diferença Padronizada de Nível a $2 \mathrm{~m}$ (D'ls,2m, nT), respectivamente, conforme equações 1 e 3 :

$\mathrm{D}_{\mathrm{nT}}=\mathrm{D}-10 \log \left(\mathrm{T} / \mathrm{T}_{\mathrm{o}}\right)$

Onde:

$D$ é a diferença de nível, em decibels, dB; 
$T$ é o tempo de reverberação da sala de recepção, em segundos;

$T_{o}$ é o tempo de reverberação de referência, em edificações, $T_{o}=0,5 \mathrm{~s}$.

Sendo a diferença de nível, D, obtida da diferença entre os níveis de pressão sonora da fonte, na sala de emissão (L1) e na sala de recepção (L2), conforme equação 2, dada em decibels, dB:

$\mathrm{D}=\mathrm{L} 1-\mathrm{L} 2$

$\mathrm{Dls}_{\mathrm{ls}, 2 \mathrm{~m}, \mathrm{nT}}=\mathrm{D}_{\mathrm{ls}, 2 \mathrm{~m}}+10 \log \left(\mathrm{T} / \mathrm{T}_{\mathrm{o}}\right)(\mathrm{dB})$

Onde:

$D_{I s, 2 m}$ é a diferença de nível a $2 \mathrm{~m}$, em decibels, $\mathrm{dB}$;

T é o tempo de reverberação da sala de recepção, em segundos;

$T_{o}$ é o tempo de reverberação de referência (edificações), $T_{o}=0,5 \mathrm{~s}$.

Por sua vez, a Diferença de Nível a $2 \mathrm{~m}\left(\mathrm{D}_{\mathrm{ls}, 2 \mathrm{~m}}\right)$ é o resultado da diferença entre o nível de pressão sonora médio do lado de fora, a $2 \mathrm{~m}$ da fachada (L1,2m), e o nível de pressão sonora médio na sala receptora (L2), conforme equação 4 :

$D_{I s, 2 m}=\mathrm{L}_{1,2 \mathrm{~m}}-\mathrm{L}_{2}(\mathrm{~dB})$

Utilizou-se nesse estudo como parâmetros para avaliar o isolamento das paredes estudadas os valores da Diferença Padronizada de Nível Ponderado, $D_{\text {n't,w e }}$ D'2m,nT,w.

\section{Medições em campo}

As medições de isolamento de ruído aéreo foram realizadas, através do método de engenharia, em duas situações: o isolamento sonoro entre partições, no caso, entre recintos de salas de estar de apartamentos contíguos, AP1 e AP2 (Figura 3); e o isolamento sonoro da fachada da sala de estar (Figura 4).

Os equipamentos utilizados nas medições das duas situações foram: Medidor Integrador de Nível Sonoro da marca $01 \mathrm{~dB}$, modelo SOLO, Classe 1; o software dBBati32; caixa acústica amplificada modelo Top 500 da marca Staner; calibrador acústico Classe 1 Cal 21 da marca $01 \mathrm{~dB}$; tripé para apoiar o medidor; e balões de borracha. A faixa de frequência adotada foi a de bandas de terço de oitava, de $100 \mathrm{~Hz}$ a $3150 \mathrm{~Hz}$.

As $\quad$ ISO $\quad 140-4 \quad$ (INTERNATIONAL ORGANIZATION FOR STANDARDIZATION, 1998a) e ISO 140-5 (INTERNATIONAL ORGANIZATION FOR STANDARDIZATION, 1998b) recomendam o uso de fonte sonora omnidirecional nas medições, porém não foi encontrado no mercado alagoano nenhum equipamento como este. Desse modo, foi feita uma adaptação, adotando uma caixa acústica comum. Com este equipamento não é possível realizar medições do tempo de reverberação através do método do ruído interrompido, o qual adota o ruído rosa, método mais usado nas avaliações em campo do desempenho acústico de residências. Optou-se, então, por utilizar o método da resposta impulsiva, tendo como ruído da fonte o gerado com o estouro de balões de borracha.

Figura 3 - Sala de estar apartamento vizinho

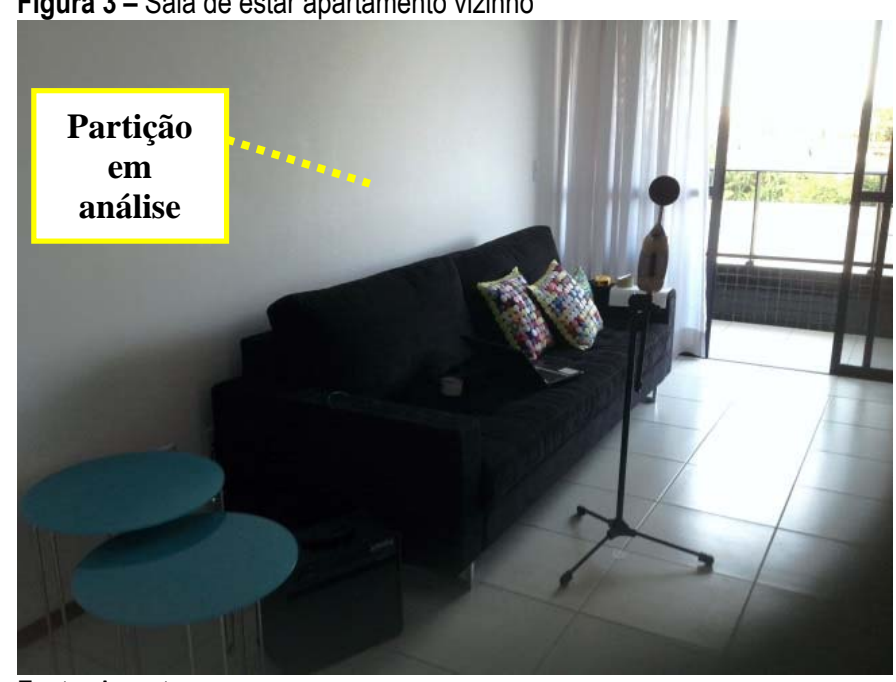

Fonte: As autoras

Figura 4 - Partição entre sala de estar e varanda

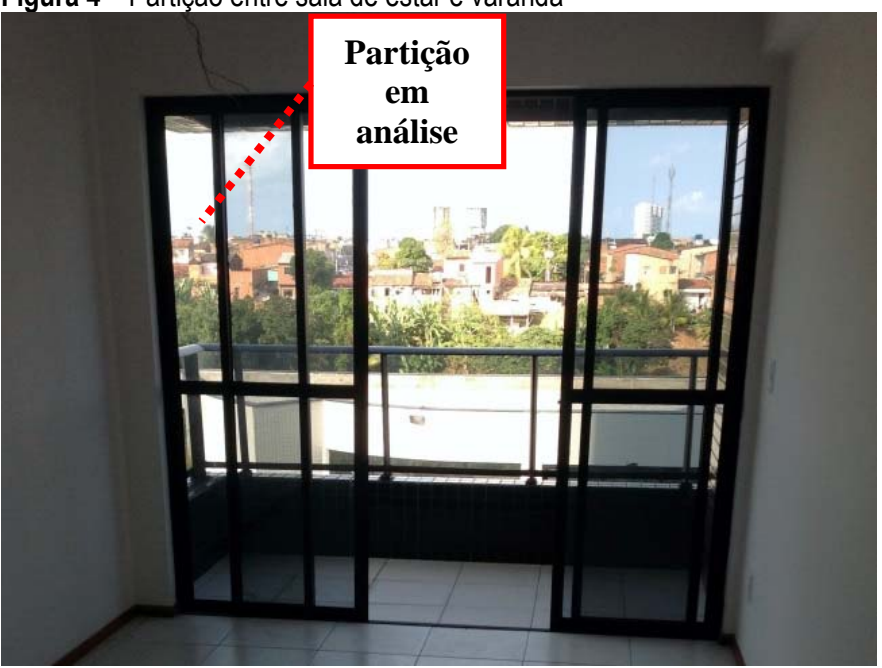

Fonte: As autoras

Para a avaliação do isolamento de ruído aéreo entre recintos, no caso, entre as salas de estar dos apartamentos vizinhos, foram seguidas as recomendações da ISO 140-4 (INTERNATIONAL ORGANIZATION FOR STANDARDIZATION, 1998a). 
As medições do nível de pressão sonora no ambiente emissor (L1) foram feitas, com duração de $6 \mathrm{~s}$ cada, com a fonte emitindo ruído branco e posicionada em dois pontos da sala emissora (F1 e F2), e com o medidor de pressão sonora em cinco posições no mesmo ambiente (E1, E2, E3, E4 e E5). Para a obtenção do nível de pressão sonora na sala receptora (L2), foi repetido o procedimento, colocando, porém, o medidor em cinco posições no ambiente receptor (R1, R2, R3, R4 e R5).

As medições do tempo de reverberação (Tr) no ambiente receptor, com $2 \mathrm{~s}$ de duração cada, teve como fonte o ruído do estouro de balões de borracha, conforme explicação anterior, seguindo o método da resposta impulsiva acústica e as recomendações da ISO 3382 (INTERNATIONAL ORGANIZATION FOR STANDARDIZATION, 1997). Os balões foram estourados a 1,2 $\mathrm{m}$ de distância do medidor. Para cada uma das três posições do medidor, foram feitos três estouros (Figura 5). Por fim, o ruído de fundo (B2) foi medido nos ambientes receptores, com a fonte desligada e três posições do medidor, as mesmas do tempo de reverberação. As posições da fonte e do medidor estão indicadas na Figura 5.

Figura 5 - Planta baixa com as posições da fonte e do microfone na situação 1 (Isolamento sonoro entre partições contíguas de apartamentos vizinhos) SITUAÇÃO 1: ENTRE APARTAMENTOS VIZINHOS (AP1 - AP2)

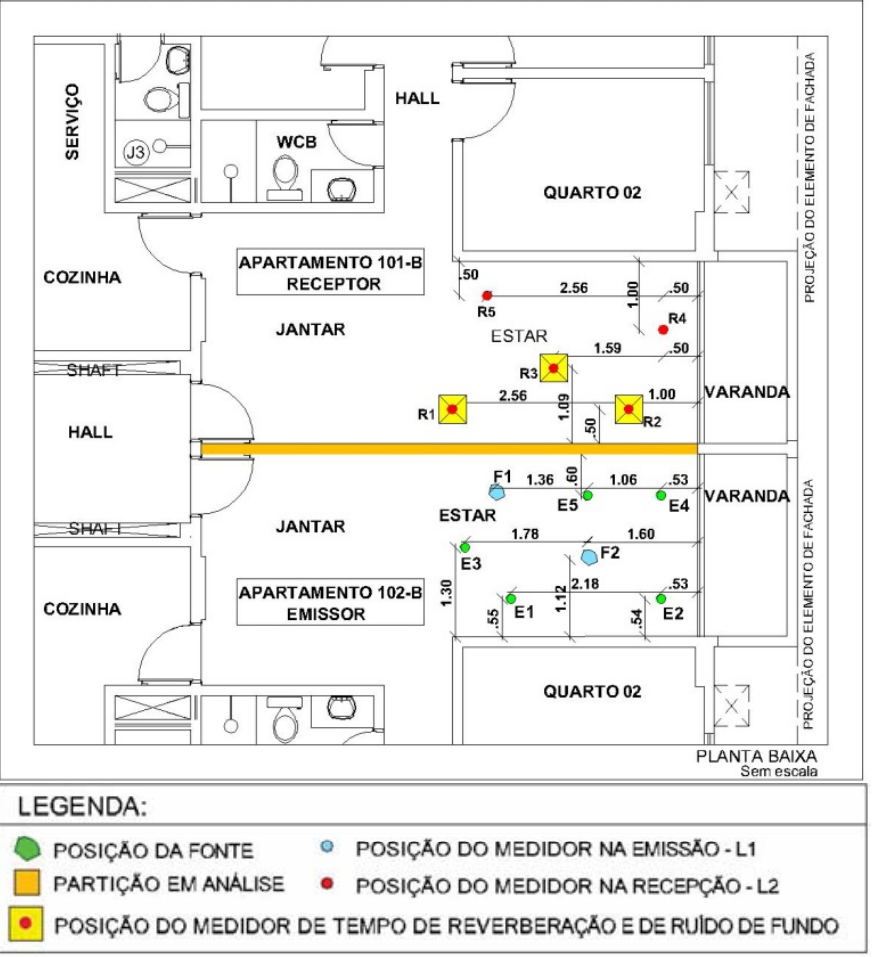

Fonte: As autoras

O método de engenharia para a medição de isolamento de ruído aéreo de fachadas, descrito na ISO 140-5 (INTERNATIONAL ORGANIZATION FOR
STANDARDIZATION, 1998b), foi aplicado na avaliação da fachada da sala de estar do objeto (Figura 6). Apesar da Norma de Desempenho (ASSOCIAÇÃO BRASILEIRA DE NORMAS TÉGNICAS, 2013) apresentar critérios apenas para fachadas de dormitórios, optou-se por adotar esses parâmetros na avaliação da fachada da sala de estar, por considerar que este ambiente, usado também para o descanso, necessita de um isolamento sonoro semelhante ao recomendado para quartos.

O primeiro passo das medições foi gerar um campo sonoro exterior, com o método de alto-falantes, utilizando o ruído branco, com a fonte emissora posicionada de modo a formar um ângulo de $45^{\circ} \mathrm{em}$ relação à normal da fachada. Cada medição teve duração de 6 segundos. A fonte foi posicionada em dois locais diferentes na área de lazer, junto à piscina do pilotis. Para cada posição da fonte, o medidor foi posicionado em três pontos a $2 \mathrm{~m}$ da fachada (E1, E2 e E3), e em cinco pontos, dentro do ambiente receptor (R1, R2, R3, R4 e R5). Em seguida, foram feitas as medições do ruído de fundo e do tempo de reverberação, seguindo as mesmas regras adotadas nas medições de isolamento entre recintos (Figura 6).

Figura 6 - Planta baixa com as posições da fonte e do microfone na situação 2 (Isolamento sonoro de fachada)



Fonte: As autoras 
O software utilizado para as medições foi o dB Bati32, através das seguintes funções: espectro padrão, para as medições de nível de pressão sonoro; tempo de reverberação; e ruído de fundo. Para a sistematização desses dados, as informações armazenadas no software foram organizadas em planilhas, facilitando a análise.

\section{Resultados e discussões}

A sistematização dos resultados encontrados e a inserção deles nas fórmulas de cálculo estabelecidas nas normas técnicas para a obtenção dos valores globais utilizados na análise quantitativa permitiu chegar às primeiras conclusões sobre o desempenho acústico do objeto de estudo.

Foi feita ainda uma análise dos elementos construtivos para tratar dos efeitos do partido arquitetônico adotado e dos materiais e técnicas de construção utilizadas sobre o isolamento sonoro aéreo de suas partições verticais.

\section{Desempenho acústico em campo}

Para que sejam feitas as análises dos resultados das medições em campo, e, assim, verificar o desempenho acústico das partições avaliadas, é preciso transformar os valores obtidos nas medições em valores globais, sendo D'nT,w para o isolamento entre apartamentos contíguos, e D'2m,nT,w para o isolamento da fachada, também conhecidos como número único. $\mathrm{O}$ primeiro passo é aplicar os valores de L1, L2 e do tempo de reverberação na fórmula de cálculo do $\mathrm{D}_{\mathrm{nT}}$ (equação 01) e do Dls,2m,nT (Equação 3).
Porém, deve ser verificada a necessidade de aplicação de correções no L2 de acordo com os resultados do ruído de fundo. Segundo a ISO 140-4 (INTERNATIONAL ORGANIZATION FOR STANDARDIZATION, 1998a), quando a diferença entre o nível de pressão sonora na sala receptora (L2) e o de ruído de fundo (B2) for menor que $6 \mathrm{~dB}$, deve-se subtrair 1,3 dB de L2. Caso a diferença entre o nível de pressão sonora e o de ruído de fundo fique entre $6 \mathrm{~dB}$ e $10 \mathrm{~dB}$ : usar a seguinte fórmula para a correção (equação $5)$ :

$\mathrm{L}=10 \log \left(10^{\mathrm{Lsb} / 10}-10^{\mathrm{Lb} / 10}\right)$

Onde:

$L=$ nível de sinal ajustado $(\mathrm{dB})$;

$L s b=$ nível de sinal e o ruído de fundo combinados $(\mathrm{dB})$;

$L_{b}=$ nível de ruído de fundo (dB).

Em seguida, é feito o cálculo para a obtenção do número único, seguindo as recomendações da ISO 7171 (INTERNATIONAL ORGANIZATION FOR STANDARDIZATION, 1996). Os valores obtidos para $\mathrm{D}_{\mathrm{nT}}$, D $2 \mathrm{~m}, \mathrm{nT}, \mathrm{D}_{\mathrm{n} T, \mathrm{w}}$ e $\mathrm{D}^{\prime}{ }_{2 \mathrm{~m}, \mathrm{nT}, \mathrm{w}}$ foram sistematizados no Quadro 2, no qual foram inseridas ainda colunas com os limites mínimos (M) estabelecidos na Norma de Desempenho NBR 15575 (ASSOCIAÇÃO BRASILEIRA DE NORMAS TÉCNICAS, 2013) para os parâmetros em análise.

Quadro 2 -Resumo dos resultados da Diferença Padronizada de Nível para partições internas $\left(D_{n T}\right)$ e para fachadas $\left(D_{2 m, n T}\right)$ e a Diferença Padronizada de Nível Ponderada para partições internas ( $\left.D_{n T w}^{\prime}\right)$ e para fachadas $\left(D^{\prime}{ }_{2 m, n T w}\right)$ em $d(B)$ nas medições

\begin{tabular}{|c|c|c|c|c|c|c|c|c|c|c|c|c|c|c|c|c|c|c|c|c|c|}
\hline \multirow{2}{*}{$\begin{array}{l}\text { Parâmetros } \\
\text { Acústicos } \\
\text { (dB) }\end{array}$} & \multirow[b]{2}{*}{ Ambientes } & \multicolumn{16}{|c|}{ Frequência (Hz) } & $\begin{array}{c}\text { Entre } \\
\text { recintos }\end{array}$ & Fachadas & $\begin{array}{c}D_{\text {nTw }}^{\prime} \\
\text { (M) }\end{array}$ & $\begin{array}{c}D^{\prime}{ }_{2 m, n T w} \\
\text { (M) }\end{array}$ \\
\hline & & 음 & $\stackrel{2}{\stackrel{2}{*}}$ & 흐 & ్ㅗ & జ్స్ & $\stackrel{\text { n) }}{m}$ & প্ণ & 오 & ஜ్రి & ర్థ & $\ddot{F}$ & ్ㅡㄹ &  & స & 䛔 & $\frac{\frac{5}{m}}{m}$ & $\begin{array}{c}D^{\prime}{ }_{n T w} \\
\text { (C;Ctr) } \\
\text { (dB) }\end{array}$ & $\begin{array}{c}\text { D'2m,nTw } \\
\text { (C;Ctr) } \\
\text { (dB) }\end{array}$ & $\begin{array}{c}\text { NBR } \\
15575 \\
\text { (ABNT. } \\
2013) \\
\text { (dB) }\end{array}$ & $\begin{array}{c}\text { NBR } \\
15575 \\
\text { (ABNT. } \\
2013 \text { ) } \\
\text { (dB) }\end{array}$ \\
\hline $\begin{array}{l}\text { Isolamento } \\
\text { sonoro } \\
\text { entre } \\
\text { recintos }\end{array}$ & $\begin{array}{l}\text { Sala de } \\
\text { estar 101B } \\
\text { - sala de } \\
\text { estar 102B }\end{array}$ & 16 & 15 & 16 & 14 & 16 & 15 & 13 & 14 & 17 & 17 & 18 & 19 & 19 & 18 & 16 & 14 & 17 & - & 40 a 44 & \\
\hline $\begin{array}{l}\text { Isolamento } \\
\text { sonoro da } \\
\text { fachada }\end{array}$ & $\begin{array}{c}\text { Fachada - } \\
\text { sala de } \\
\text { estar 101B }\end{array}$ & 25 & 23 & 23 & 22 & 25 & 24 & 22 & 23 & 25 & 23 & 24 & 24 & 24 & 24 & 25 & 23 & - & 24 & & $\geq 25$ \\
\hline
\end{tabular}

Fonte: As autoras 


\section{Análise dos elementos construtivos das partições}

Após analisar os resultados encontrados de forma quantitativa, foi feita a análise qualitativa, levando em consideração as estratégias de projeto, as técnicas e os materiais adotados na construção dos objetos de estudo.

A análise da Figura 7, com a planta baixa indicando os resultados das medições em cada partição analisada na sala de estar do objeto de estudo, mostra que, de certa forma, houve um descuido com o conforto acústico e com a privacidade na fase de projeto.

Figura 7 - Recorte da planta baixa do objeto de estudo indicando os resultados encontrados e os limites da NBR 15575

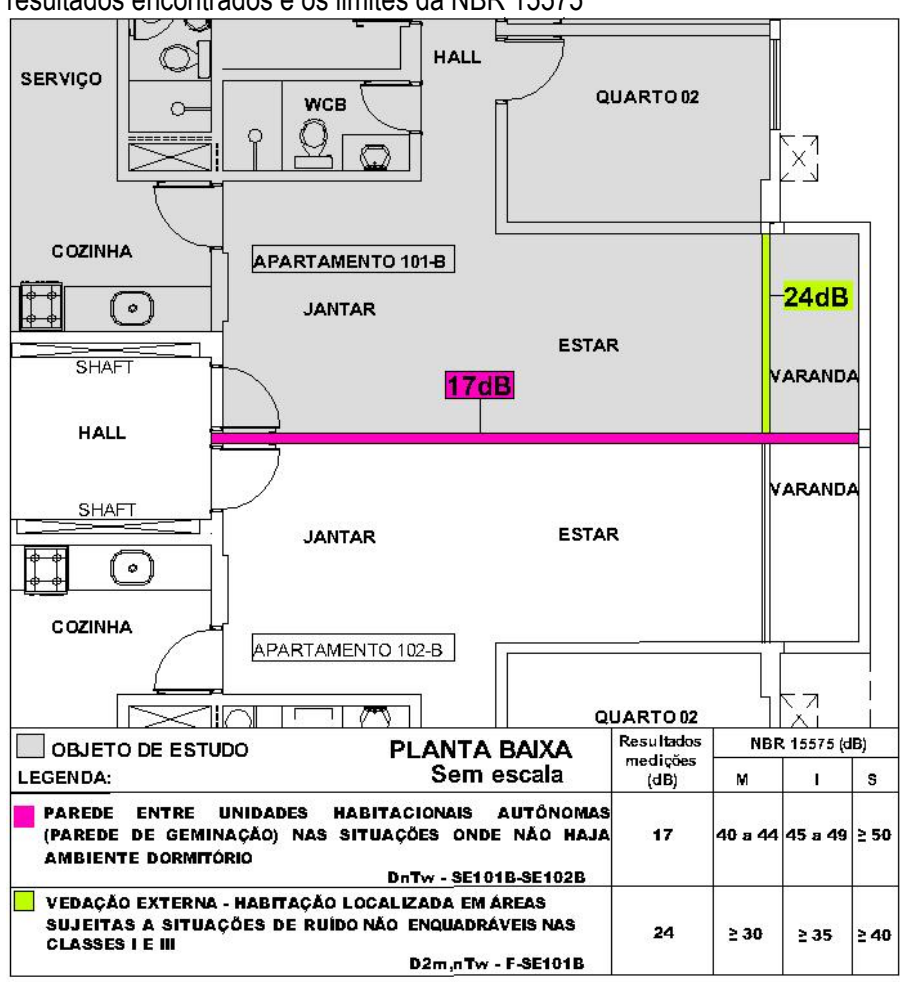

Fonte: As autoras

O posicionamento das esquadrias dos apartamentos vizinhos lado a lado favorece a passagem dos sons de uma unidade habitacional para a outra (Figura 7). Desse modo, a locação das portas de acesso aos apartamentos e às varandas deveria prever um afastamento entre elas.

Os materiais construtivos empregados nas esquadrias e nas paredes da sala de estar também não favoreceram a amortização da passagem dos ruídos entre apartamentos vizinhos e daqueles provenientes do exterior da edificação. Portas de correr convencionais, devido às frestas nos trilhos e aos espaços entre as folhas, são mais permeáveis ao ruído que as de giro ("de abrir"), por exemplo. Porém, já existem soluções para esses problemas: preenchimento das frestas dos trilhos com escovas de poliuretano expandido e um sistema de vedação mais eficiente no travamento das folhas.

A alvenaria singela com blocos cerâmicos de espessura reduzida, $9 \mathrm{~cm}$, para partições entre apartamentos vizinhos e para as fachadas não proporciona resistência suficiente à passagem dos ruídos. As divisórias para esses tipos de ambientes, cujas fontes de ruído não estão sob o controle do usuário do ambiente de recepção, devem ser mais densas para impedir a passagem dos ruídos indesejáveis da vizinhança e para evitar que os sons oriundos das atividades realizadas na sala de estar em estudo não extrapolem os limites da unidade habitacional, incomodando os vizinhos $\mathrm{e}$ prejudicando a privacidade dos usuários.

As constatações apresentadas destacam problemas de projeto bastante frequentes nos projetos arquitetônicos dos edifícios multifamiliares em Maceió-AL. A implantação das sugestões propostas resultaria na melhoria considerável do conforto acústico dos ambientes com baixo impacto no custo total do empreendimento, por serem alterações de projeto. Geralmente, desempenhos elevados oneram o custo da construção, mas a redução no consumo e o maior conforto pode amortizar o investimento inicial. As exigências da NBR 15575 (ASSOCIAÇÃO BRASILEIRA DE NORMAS TÉGNICAS, 2013) já têm provocado uma repercussão nos fabricantes e fornecedores de sistemas construtivos que, para atender às demandas dos construtores, estão aumentando a oferta de produtos "acústicos", o que pode refletir na redução do preço, tornando as soluções economicamente viáveis para construtores e proprietários.

\section{Conclusão}

Ao serem comparados os resultados das duas variáveis avaliadas, foi constatado que a situação mais crítica é a do isolamento sonoro da parede entre os apartamentos vizinhos, situação que pode gerar sérios problemas de vizinhança. $\mathrm{O}$ resultado obtido foi inferior à metade do mínimo exigido pela NBR 15575 (ASSOCIAÇÃO BRASILEIRA DE NORMAS TÉGNICAS, 2013), evidenciando a fragilidade acústica da divisória em alvenaria de blocos cerâmicos furados entre as duas unidades habitacionais (Quadro 2). Dificilmente essa diferença de $23 \mathrm{~dB}$ entre o D'nTw resultante e o mínimo exigido pela norma poderá ser corrigida por projetos acústicos tardios e com medidas paliativas economicamente viáveis. 
Segundo Câmara Brasileira da Indústria da Construção (2013), o índice de redução sonora ponderada (R'w) proporcionada por blocos vazados de cerâmica com 9 $\mathrm{cm}$ de espessura, com cerca de $120 \mathrm{~kg} / \mathrm{m}$ de massa e revestimento com $1,5 \mathrm{~cm}$ de espessura de argamassa de gesso em cada face, medida em laboratório, é de $38 \mathrm{~dB}$. Esse valor é inferior ao desempenho acústico mínimo exigido pela NBR 15575 (ASSOCIAÇÃO BRASILEIRA DE NORMAS TÉCNICAS, 2013) para componentes construtivos de paredes entre unidades habitacionais autônomas (parede de geminação) nas situações onde não haja ambiente dormitório: entre 45 e $49 \mathrm{~dB}$. Desse modo, já era previsto que, nas medições em campo, o isolamento sonoro das paredes compostas por esses tijolos vazados também não atingisse o desempenho acústico mínimo exigido.

$\mathrm{O}$ isolamento sonoro da partição da fachada da sala de estar, protegida por uma varanda com $1,20 \mathrm{~m}$ de profundidade, apesar de não ter atingido o limite mínimo estabelecido pela Norma de Desempenho, 25 $\mathrm{dB}$, apresentou um valor de $\mathrm{D} 2 \mathrm{~m}, \mathrm{nT}$ muito próximo, 24 dB (Quadro 2). Acredita-se que a presença da varanda tenha contribuído para reduzir o ruído incidente na sala de estar e, consequentemente, compensar a fragilidade acústica da porta de alumínio com vidro comum $6 \mathrm{~mm}$ que compõe cerca de $85 \%$ da área da partição em análise. Esse isolamento pode ser melhorado, de modo a se adequar aos limites da norma, substituindo a esquadria existente por uma de melhor desempenho acústico, com melhores sistemas de vedação para dificultar a passagem dos ruídos externos.

Não foi possível realizar a comparação com os dados técnicos de fabricantes das esquadrias de alumínio com vidro pela falta de tais informações. Hoje no mercado há uma carência de dados referentes ao desempenho acústico desses elementos construtivos, os quais serviriam como um auxílio ao projetista na escolha das portas e janelas.

Esta análise retrata a importância do tratamento acústico na fase inicial do projeto, o que evitaria os transtornos causados pela incidência de ruídos indesejáveis e pela falta de privacidade, e os gastos para melhorar o desempenho acústico dos ambientes.

\section{Referências}

ASSOCIAÇÃO BRASILEIRA DE NORMAS TÉGNICAS. NBR 15575: Edificações Habitacionais - Desempenho. Rio de Janeiro: ABNT, 2013.

\section{CÂMARA BRASILEIRA DA INDÚSTRIA DA CONSTRUÇÃO. Desempenho de edificações habitacionais: Guia} orientativo para atendimento à norma ABNT 15575/2013. Fortaleza: Gadioli Cipolla Comunicação, 2013.

FERREIRA NETO, Maria de Fátima. Nível de conforto acústico: uma proposta para edifícios residenciais. 2009. 257 f. Tese (Doutorado em Engenharia Civil) - Programa de Pós-Graduação da Faculdade de Engenharia Civil, Arquitetura e Urbanismo, Universidade Estadual de Campinas, Campinas, São Paulo, 2009.

INTERNATIONAL ORGANIZATION FOR STANDARDIZATION. ISO 140-4 Acoustics -- Measurement of sound insulation in buildings and of building elements -- Part 4: Field measurements of airborne sound insulation between rooms. Geneva, 1998a.

ISO 140-5 Acoustics -- Measurement of sound insulation in buildings and of building elements -- Part 5: Field measurements of airborne sound insulation of façade elements and façades. Geneva, 1998b.25p

ISO 717-1 Acoustics - Rating of sound insulation in buildings and of building elements. Part 1: Airborne sound insulation. 2nd ed. Geneva, 1996.

Geneva, 1997.

ISO 3382 Acoustics -- Measurement of the reverberation time of rooms with reference to other acoustical parameters.

Geneva, 1997.

\footnotetext{
${ }^{1}$ Rafaella Gristina Teixeira Penedo

Arquiteta e Urbanista. Mestre em Arquitetura e Urbanismo pela UFAL. Endereço postal: Rua Deputado Rubens Canuto, 61A. Apto 402, Ponta Verde, Maceió, AL, Brasil, CEP 57035-200.

${ }^{2}$ Maria Lúcia Gondim da Rosa Oiticica

Arquiteta e Urbanista. Doutora em Engenharia Civil pela UNICAMP. Endereço postal: Rua Isaac Gondim, Lote 5/6, Jardim Petrópolis, Maceió, AL, Brasil, CEP 57080-600.
} 